\title{
Seasonal Variations in Isoprene Emissions from a Boreal Aspen Forest
}

\author{
J. D. FUENTES \\ Department of Environmental Sciences, University of Virginia, Charlottesville, Virginia \\ D. WANG \\ Environmental Protection Service, Environment Canada, Ottawa, Ontario, Canada \\ L. GU \\ Department of Environmental Sciences, University of Virginia, Charlottesville, Virginia
}

(Manuscript received 12 February 1998, in final form 14 July 1998)

\begin{abstract}
The primary objective of this study was to understand the environmental and seasonal controls over isoprene emissions from a boreal forest ecosystem whose isoprene source came from trees of the same species and age. A further objective was to establish an annual budget of isoprene emitted from a remote boreal forest and thus assess uncertainties associated with seasonal isoprene emission inventories. The onset of isoprene emissions occurred two weeks after the forest attained its maximum leaf area. Scaled to the foliage level, averaged isoprene fluxes approached $10 \pm 5 \mathrm{nmol} \mathrm{m} \mathrm{m}^{-2} \mathrm{~s}^{-1}$ in the spring. During the middle of the growing season averaged isoprene emissions amounted to $28 \pm 4 \mathrm{nmol} \mathrm{m} \mathrm{m}^{-2} \mathrm{~s}^{-1}$, whereas late summer values reached $16 \pm 2 \mathrm{mmol} \mathrm{m}^{-2} \mathrm{~s}^{-1}$. These isoprene capacities were normalized to $25^{\circ} \mathrm{C}$ and photosynthetically active radiation of $1000 \mu \mathrm{mol} \mathrm{m}^{-2} \mathrm{~s}^{-1}$. Given the strong seasonality observed in isoprene emissions, the authors propose to include seasonally adjusted emission rates to derive isoprene inventories for the entire foliage growing cycle. With an active biomass of $144 \mathrm{~g} \mathrm{~m}^{-2}$, using a seasonally adjusted emission rate in a one-dimensional multilayered model it is estimated that during 1994 the boreal aspen forest emitted $32 \mu \mathrm{mol}$ of isoprene per square meter. Such isoprene source strength represented approximately $1 \%$ of the photosynthetically fixed carbon by the aspen forest. In addition to the seasonal controls dictated by the inherent plant metabolic activity, low temperatures $\left(<10^{\circ} \mathrm{C}\right)$ strongly reduced the amplitude of diurnal isoprene emissions.
\end{abstract}

\section{Introduction}

Certain plant genera, especially many deciduous tree species, release large amounts of isoprene (2-methyl 1,3-butadiene $\left.=\mathrm{CH}_{2}=\mathrm{C}\left(\mathrm{CH}_{3}\right)-\mathrm{CH}=\mathrm{CH}_{2}\right)$ to the atmosphere. At the global scale, the estimated phytogenic isoprene flux is approximately $5 \times 10^{14} \mathrm{~g} \mathrm{C} \mathrm{yr}^{-1}$ (Guenther et al. 1995). Owing to its rapid gas-phase daytime reactions with ozone $\left(\mathrm{O}_{3}\right)$ and the hydroxyl radical $(\mathrm{OH})$, isoprene can also impact both regional and global chemistry. By competing with greenhouse gases such as methane for $\mathrm{OH}$, isoprene can influence the oxidation capacity of the troposphere. Reactions of isoprene with $\mathrm{OH}$ produce carbon monoxide and carbonyl compounds (i.e., methyl vinyl ketone and methyl acrolein), which once in environments rich in nitrogen

Corresponding author address: José D. Fuentes, Department of Environmental Sciences, Clark Hall, University of Virginia, Charlottesville, VA 22903.

E-mail: jf6s@virginia.edu oxides under favorable meteorological conditions, can lead to the formation of ozone (Chameides et al. 1988; Fehsenfeld et al. 1992). Because isoprene is linked to the carbon fixation pathway in plants (Monson and Fall 1989; Sharkey et al. 1991), there is also scientific interest in discerning the fraction of photosynthetically fixed carbon entering the atmosphere in the form of isoprene. Therefore, understanding the magnitude and seasonal patterns of emissions is required to quantify and assess isoprene impacts on regional and global oxidant formation, and on atmospheric carbon cycling.

To investigate the role of isoprene in regional oxidant formation, biospheric modeling systems exist to derive isoprene inventories. These systems consider emission rates at the foliage level, active biomass, and microclimate characteristics within vegetated landscapes to integrate emissions to the canopy (Baldocchi et al. 1995; Fuentes et al. 1996; Lamb et al. 1996) and ecosystem (Geron et al. 1994; Guenther et al. 1994; Lamb et al. 1993) scales. At the canopy level, comparisons between modeled and measured isoprene fluxes show discrep- 
ancies ranging from $20 \%$ to $200 \%$, with models overestimating emissions (Baldocchi et al. 1995; Fuentes et al. 1995; Geron et al. 1997; Guenther et al. 1996; Lamb et al. 1996). During the middle of the growing season, modeled isoprene emissions are more reliable and agree within $50 \%$ of measured quantities. Major uncertainties in inventories include the vegetation surveys incorporated in models and associated scaling of emission algorithms from leaves to trees of different species and ages. Another reason models may provide unrealistic scaling of isoprene emissions in mixed stands is due to the different "footprints" of isoprene emitting vegetation, the source strength varying with wind direction and atmospheric stability regime (Lamb et al. 1996). Moreover, in spite of isoprene emissions changing considerably over the growing season (Grinspoon et al. 1991; Fuentes et al. 1995; Monson et al. 1994), emission rates characterizing mid-growing season conditions are sometimes used with modeling systems to derive inventories for the entire growing season.

Canopy- and ecosystem-scale isoprene fluxes are needed to provide data for testing and improving inventory modeling systems. Existing forest canopy isoprene flux data come largely from short-term studies, representing conditions during the middle of the growing season (Baldocchi et al. 1999). Studies on seasonal isoprene emissions at the ecosystem level are rare. Therefore, in 1994 we conducted a field research project to determine isoprene fluxes from a deciduous forest in the southern boreal region of Canada. The primary objective of this study was to characterize the environmental and seasonal controls over isoprene emissions from a forest ecosystem whose isoprene source came from trees of the same species and age. A further objective was to establish an annual budget of isoprene emitted from a remote boreal forest and assess the uncertainties associated with seasonal isoprene emission inventories. The information presented here has important consequences relating to the isoprene content of the remote environment where it can alter the oxidation capacity of the atmosphere.

\section{Site description and measurements}

The data reported here were obtained during April to September 1994. This study was conducted as part of the Boreas Ecosystem Atmosphere Study (BOREAS) project, and therefore additional measurements exist on energy and trace gas fluxes for the aspen forest (Black et al. 1996; Blanken et al. 1997; Sellers et al. 1995; Simpson et al. 1997).

\section{a. Site description}

Measurements were obtained at a forest stand of trembling aspen (Populus tremuloides), situated in the southern boreal forest of Canada $\left(53.7^{\circ} \mathrm{N}, 106.2^{\circ} \mathrm{W}\right)$. Randomly situated throughout the landscape, the forest also

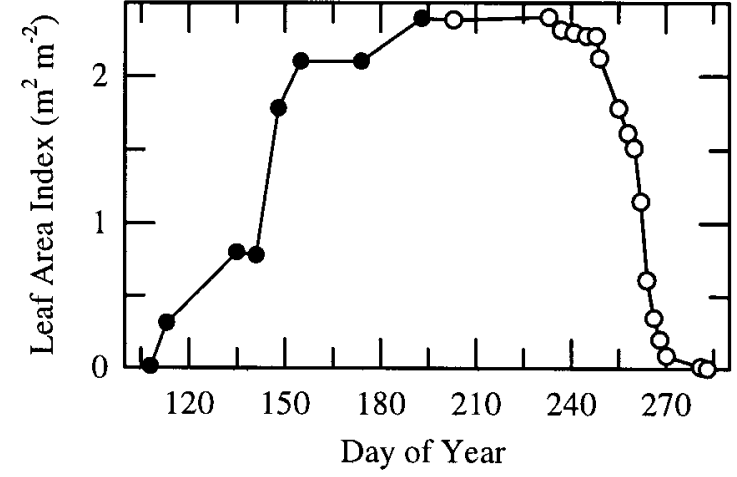

FIG. 1. The seasonal trend of LAI for the aspen forest during the 1994 growing season. The data denoted by solid circles (O) were adopted from Black et al. (1996), whereas the data represented by open circles $(\bigcirc)$ were derived from autumnal leaf-litter fall measurements.

included a small percentage $(<8 \%)$ of balsam poplar (Populus balsamifera), white spruce (Picea glauca), and black spruce (Picea mariana). During the 1994 growing season the height of this 70-yr-old aspen forest averaged $22 \mathrm{~m}$ and had a final leaf area index (LAI) of 2.4 (Fig. 1). The canopy architecture featured an open trunk space between 2 and $15 \mathrm{~m}$ without foliage, and aspen leaves were distributed in the layer between 15 and $22 \mathrm{~m}$. The stand density was approximately 900 stems ha ${ }^{-1}$ and average tree diameter at the $1.5-\mathrm{m}$ height was $17 \mathrm{~cm}$. Between the ground and $2 \mathrm{~m}$ a hazelnut (Corylus cornuta) understory with an LAI of 3.2 (Black et al. 1996) existed throughout the landscape. To support measurements inside and above the canopy, a 37-m scaffold tower was established in 1993. From the tower site the fetch extended several kilometers in all directions. The site was flat and suited to make eddy covariance and gradient-type flux density measurements.

Final LAI of the aspen forest was determined by collecting the autumnal leaf-litter fall. Leaves were collected in baskets with upper diameter $0.5 \mathrm{~m}$, lower diameter $0.4 \mathrm{~m}$, and depth $0.3 \mathrm{~m}$. Before leaves began to fall (20 August) 60 baskets were deployed along four transects, each extending $25 \mathrm{~m}$, in the vicinity of the tower. The collected leaves were taken to the laboratory and soaked in water for several hours before measuring the planar area using an area meter (model LI-3000, LICor Inc., Lincoln, NE). Neumann et al. (1989) provided the details on this method of determining forest LAI. Black et al. (1996) determined seasonal LAI measurements using a plant canopy analyzer (model LAI2000, LICor Inc.). The seasonal LAI for aspen foliage (Fig. 1) was used to estimate seasonal isoprene fluxes.

\section{b. Microclimate and flux measurements}

During April to September in 1994 both microclimate and flux measurements were accomplished by mounting instruments on the scaffold tower. Seasonal measure- 
ments of wind speed and direction (R. M. Young anemometer model 0571, Traverse City, MI), incoming solar radiation (Model PSP Eppley pyranometer, Newport, $\mathrm{RI}$ ), net radiation (model S-1 net pyrradiometer, Swissteco Instruments, Oberriet, Switzerland), photosynthetically active radiation (PAR, Model LI190SA, LICor Inc.), and relative humidity (Model MP-100, Rotronic Instrument Corp., Huntington, NY) were made above the forest. Temperature of the forest crown (20-22 m above the ground) was measured with an infrared thermometer (model 2000A, Everest Interscience Inc., Fullerton, CA). Air temperature measurements were made as well at 12 levels above the ground using ventilated and radiation shielded copper-constantan thermocouples. Microclimate data were acquired using dataloggers (model CS21XL, Campbell Scientific Inc., Logan, UT), which provided half-hourly averaged quantities.

Eddy covariance fluxes for momentum $(\tau)$, virtual heat $\left(H_{v}\right)$, carbon dioxide, and water vapor were determined throughout the growing season using three-dimensional sonic anemometers (model DAT-310, Kaijo Denki Ltd., Tokyo, Japan) in combination with appropriate fast-response gas analyzers (model LI-6262, LICor Inc.). The data $\left(\tau, H_{v}\right)$ were acquired at $100 \mathrm{~Hz}$ and block averaged to $20 \mathrm{~Hz}$. From the raw data, halfhourly fluxes were calculated. For this study, such fluxes were further reduced to hourly averages to obtain the contextual eddy covariance data required to derive the atmospheric eddy diffusivities used in the calculation of isoprene fluxes. Black et al. (1996) provided more details on the eddy covariance measurements.

To determine isoprene concentration gradients $(\partial \chi / \partial z)$, air was drawn at fast flow rates $\left(>20 \mathrm{~L} \mathrm{~min}^{-1}\right)$ through cleaned Teflon tubing (0.5" ID) from two intakes placed at 27 and $39 \mathrm{~m}$ above the ground. Before isoprene concentration gradient measurements commenced, air of known isoprene concentration was passed through the sampling lines to assess isoprene losses. The detected isoprene losses were small, amounting to less than $2 \%$. Atmospheric samples from the two intakes were collected in 3.2-L electropolished canisters. Isoprene concentrations were measured using gas chromatography (GC, model 5890, Hewlett Packward, Palo Alto, CA) coupled with a flame ionization detector (FID). Because atmospheric isoprene levels existed in trace amounts, the analyte required a preconcentration that was achieved by passing air samples through cryogenically cooled traps packed with glass beads. During sample preconcentration, trap temperatures remained constant at $-150^{\circ} \mathrm{C}$ and were controlled through computer software. Samples of known flow rate and preset volume passed the traps before concentrated analytes were introduced to the chromatographic column (HP-1, $50 \mathrm{~m} \times 0.31 \mathrm{~mm}$ ID, $1-\mu \mathrm{m}$ film thickness) after thermal desorption at $120^{\circ} \mathrm{C}$. Determined by replicate of sample analysis, isoprene analytical precision was within $4 \%$ at about 1.0 parts per billion on a volume basis (ppbv) and $7 \%$ at mixing ratios less than $0.2 \mathrm{ppbv}$. The detection
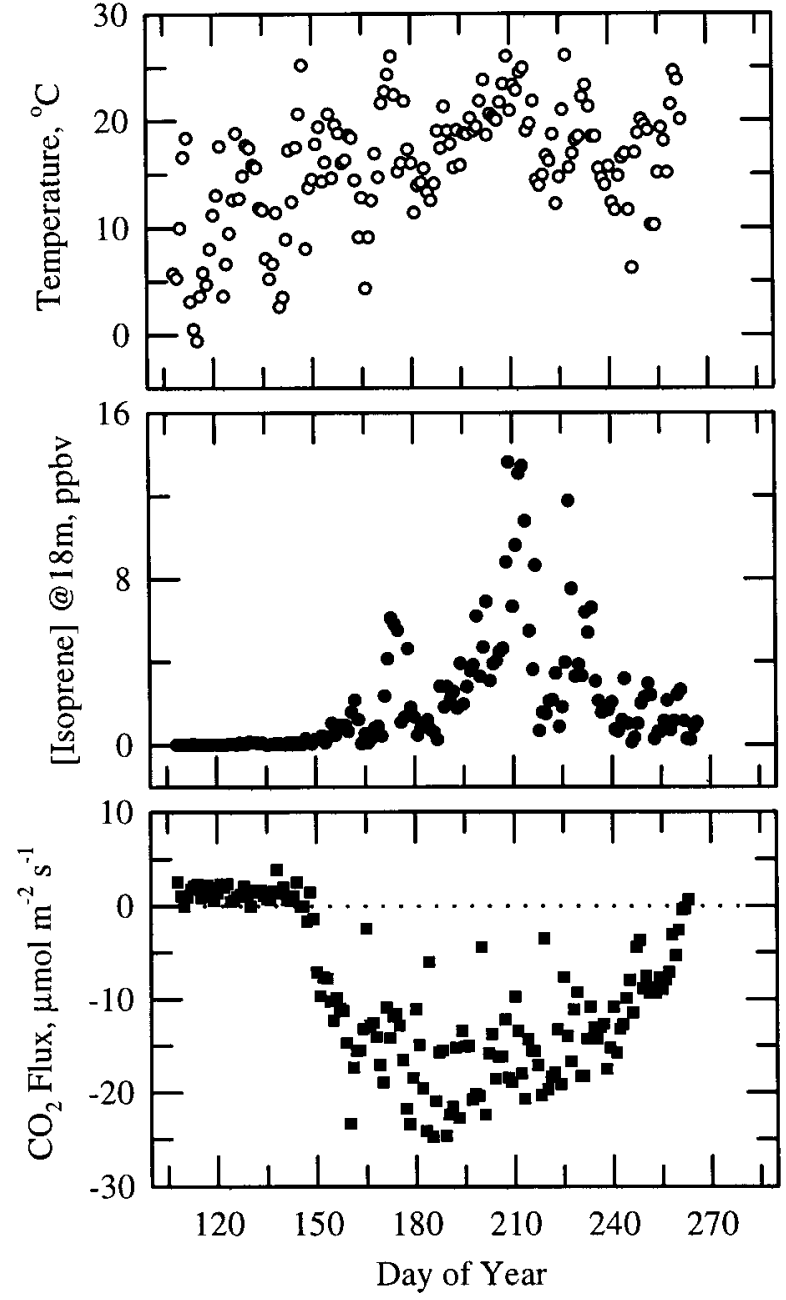

FIG. 2. Averaged canopy temperature $(\bigcirc)$, ambient isoprene mixing ratio (1) measured within the forest crown, and averaged carbon dioxide flux density ( $\square$ ) above the forest during 1200-1500 LT in 1994.

limit was 0.01 ppbv. Further details on GC-FID calibration protocols are provided elsewhere (Fuentes et al. 1996). To characterize the most dominant anthropogenic and biogenic volatile organic compounds from April to September, ambient sampling was achieved within the forest crown during 1200-1500 local time. Only ambient isoprene mixing ratios are presented here (Fig. 2) to illustrate the seasonal patterns.

The isoprene fluxes were determined using the integrated flux-gradient approach based on the MoninObukhov similarity hypothesis (Monin and Obukhov 1954). In this method, it is assumed that the isoprene flux can be characterized by the product of $\partial \chi / \partial z$ defined between two levels (27 and $39 \mathrm{~m}$ above the ground) above the isoprene source and an atmospheric eddy diffusivity $\left(K_{\chi}\right)$, as shown in (1):

$$
F_{\chi}=-K_{\chi} \frac{\partial \chi}{\partial z}
$$


The $K_{\chi}$ values were calculated based on hourly averaged, eddy-covariance measurements of momentum (which provided the friction velocity) and virtual heat fluxes (required in the diabatic correction functions for heat). Because the isoprene "footprint" source area had trees of the same species and age, the upper and lower intakes sampled air representing equal source strength and thus minimum uncertainties are expected in isoprene concentration gradients. Simpson et al. (1997) provided a flux source footprint analysis for the aspen forest. Due to uncertainties associated with determination of eddy diffusivities and measurements of isoprene concentration gradients, following Sinclair et al. (1975), the estimated uncertainty in isoprene fluxes is less than $30 \%$. Further details on theoretical background and uncertainties associated with gradient diffusion fluxes are provided by Fuentes et al. (1996) and Simpson et al. (1997).

Following the measurement protocols outlined before (Fuentes and Gillespie 1992; Fuentes et al. 1996), leaf isoprene emissions were determined during 10 days in June to September to find what local plant species emitted isoprene and to establish diurnal cycles of isoprene emission rates. The plant species present within the flux footprint of the measurement tower (within a radius of $\sim 800 \mathrm{~m}$ ) were trembling aspen, balsam poplar, and hazelnut. Hazelnut plants did not release isoprene, whereas trembling aspen and poplar trees exhibited similar isoprene emission rates defined at the leaf temperature of $25^{\circ} \mathrm{C}$ and photosynthetically active radiation (PAR) of $1000 \mu \mathrm{mol} \mathrm{m}{ }^{-2} \mathrm{~s}^{-1}$.

\section{Presentation and discussion of isoprene measurements}

\section{a. Seasonal ambient isoprene levels}

Figure 2 includes isoprene mixing ratios measured within the forest crown during 1200-1500 LT. Because temperature influences isoprene emissions through the kinetics of the enzyme responsible for isoprene biosynthesis (Monson et al. 1992), averaged canopy temperature data are also shown (Fig. 2). Since isoprene is linked to carbon fixation (Monson and Fall 1989), we report averaged $\mathrm{CO}_{2}$ fluxes to indicate the level of forest-atmosphere $\mathrm{CO}_{2}$ exchange [the $\mathrm{CO}_{2}$ fluxes were also reported by Black et al. (1996)]. Isoprene mixing ratios varied considerably with growing season. Before leaf bud break ( $<$ day 120$)$, isoprene mixing ratios stayed about 0.01 ppbv, which according to Young et al. (1997) represents the prevailing isoprene levels observed in the southern boreal forests of Canada during the wintertime. Leaves expanded rapidly and attained full expansion by day 150, with maximum LAI of 2.4. Leaf area remained constant until day 200 and thereafter leaves started to senesce and abscise (Fig. 1). In response to increasing emissions as foliage became fully developed ( $\sim$ day 150 ) isoprene mixing ratios progressively increased

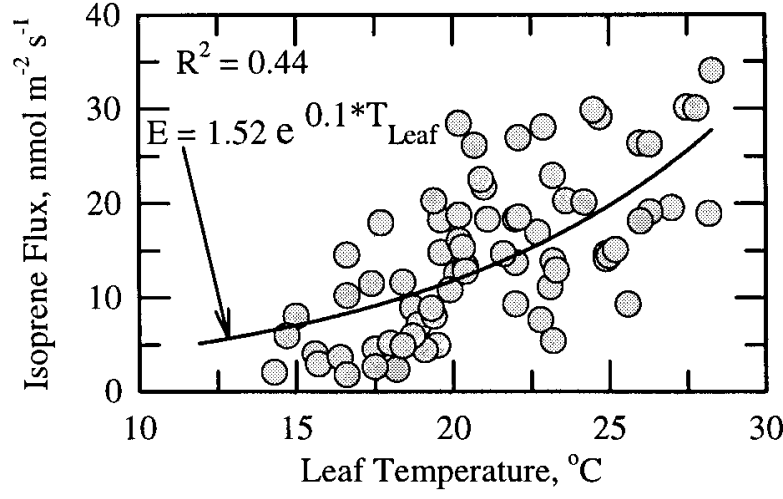

FIG. 3. The effect of leaf temperature on isoprene emission of aspen leaves. Emission rates are expressed on a unit of leaf area. Data were obtained during selected days in the period 16 Jul-12 Sep 1994.

with growing season. Maximum isoprene mixing ratios were measured during the middle of the growing season (days 200-210), with peak levels reaching nearly 16 ppbv. These maximum isoprene levels coincided with peak canopy temperature of $25^{\circ} \mathrm{C}$. Isoprene emissions (Figs. 4, 5, and 6) and the resultant ambient levels were strongly modulated by canopy temperature. Thus, the low isoprene levels $(<1 \mathrm{ppbv})$ measured during days 200 and 210 occurred in response to low emissions that were associated with low temperatures (Fig. 2). Ambient isoprene mixing ratio measurements stopped on day 268 when senescing leaves on trees were still releasing isoprene. As a result, toward the end of the growing season isoprene levels remained sufficiently above $0.1 \mathrm{ppbv}$. The aspen forest became a carbon sink after it became fully leafed (Figs. 1 and 2). Maximal rates of noontime $\mathrm{CO}_{2}$ uptake exceeded $-25 \mu \mathrm{mol} \mathrm{m}{ }^{-2} \mathrm{~s}^{-1}$ during days 180-210. Details on the relationship between $\mathrm{CO}_{2}$ and isoprene fluxes on a diurnal basis are provided below in section 3c.

\section{b. Leaf isoprene emission rates}

To illustrate the magnitude of isoprene emissions at the foliage level for the aspen trees, the leaf-based fluxes when PAR exceeded $200 \mu \mathrm{mol} \mathrm{m}{ }^{-2} \mathrm{~s}^{-1}$ were grouped and correlated against temperature (Fig. 3). These data include the period during 16 July to 12 September 1994. The observed variability in isoprene fluxes likely resulted due to natural changes in emission rates among leaves of different biological vitality. As expected, isoprene emissions increased exponentially with foliage temperature as temperature is related to the energy required in the activation of isoprene biosynthesis (Kuzma and Fall 1993). With the exception of one data point, isoprene fluxes were less than $30 \mathrm{nmol}\left(\mathrm{C}_{5} \mathrm{H}_{8}\right) \mathrm{m}^{-2}$ (leaf area) $\mathrm{s}^{-1}$. These isoprene emission rates are within the range of reported values $\left(<40 \mathrm{nmol} \mathrm{m} \mathrm{m}^{-2} \mathrm{~s}^{-1}\right)$ for aspen leaves (Fuentes et al. 1995; Monson et al. 1994; Sharkey et al. 1991). When isoprene fluxes are scaled according 

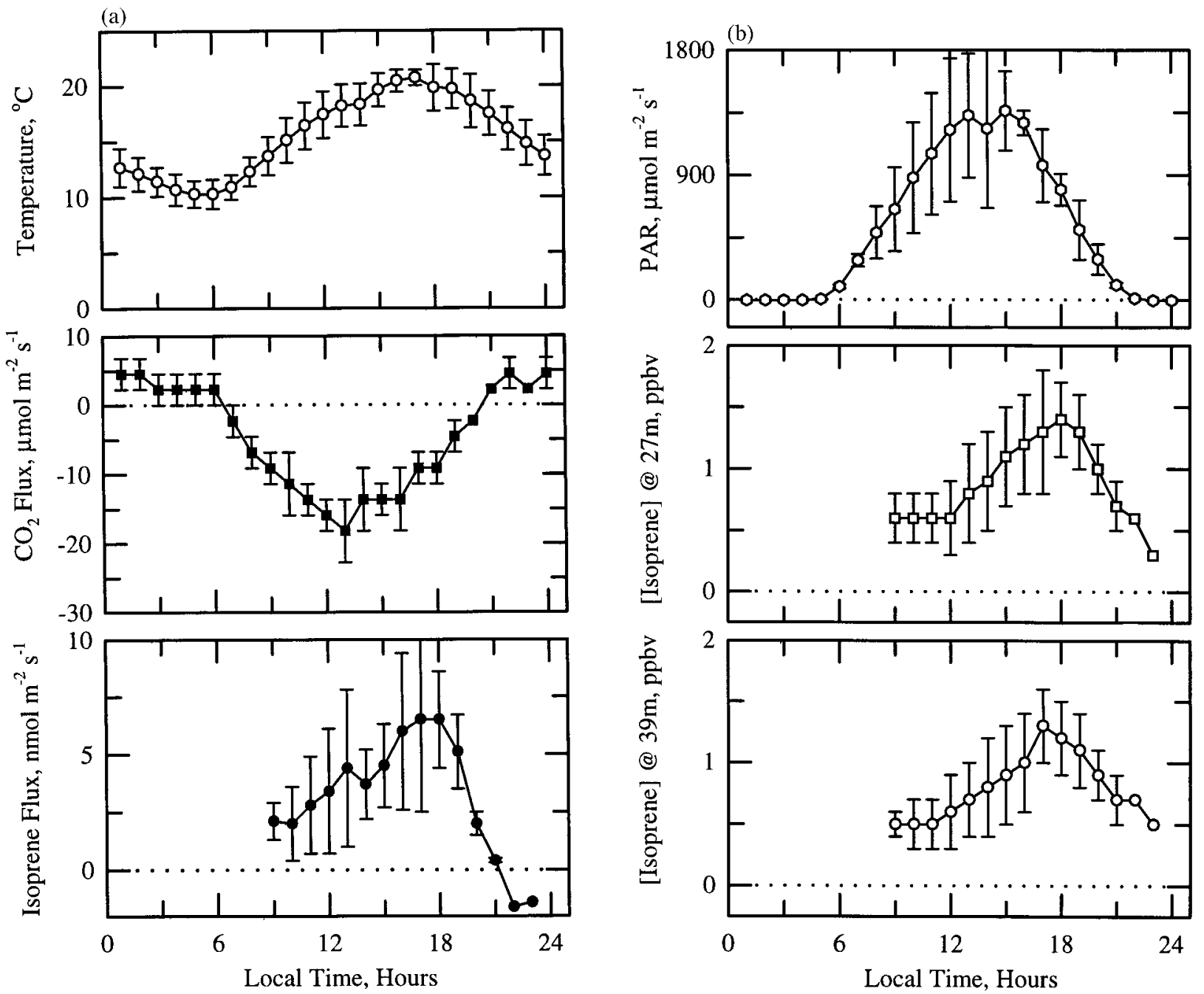

FIG. 4. (a) Averaged diurnal canopy temperature $(\bigcirc)$, carbon dioxide $(\square)$, and isoprene flux densities $(\mathbf{O})$ measured during spring $(6-19$ Jun) 1994. The bars denote \pm 1 std dev from the mean values. (b) Averaged diurnal photosynthetically active radiation (PAR, $\diamond$ ) and ambient isoprene mixing ratios measured at $27(\square)$ and $39(\bigcirc) \mathrm{m}$ above the ground during spring (6-19 Jun) 1994. The bars denote \pm 1 std dev from the mean values.

to the Guenther et al. (1993) emission algorithm at leaf temperature of $25^{\circ} \mathrm{C}$ and PAR of $1000 \mu \mathrm{mol} \mathrm{m}{ }^{-2} \mathrm{~s}^{-1}$, the averaged emission rate was $26.6 \pm 10.2 \mathrm{nmol} \mathrm{m}^{-2}$ $\mathrm{s}^{-1}$ (Fig. 3). Given that cuvette measurements precluded the leaf development and senescence periods, this emission rate may be taken to represent midgrowing conditions for the aspen forest. Below we discuss how the canopy isoprene fluxes changed with growing season.

\section{c. Canopy isoprene fluxes}

Canopy isoprene flux measurements commenced in spring (26 May) and continued until the beginning of the autumnal period (20 September) when aspen leaves started to abscise (Fig. 1). During spring, while leaves were growing, canopy isoprene fluxes were below levels of detection until two weeks after full leaf expansion.
Because canopy isoprene fluxes were not continuously determined throughout the growing season, we segregated the data to obtain averaged fluxes for spring, summer, and late summer periods. Averaged quantities for canopy temperature, and $\mathrm{CO}_{2}$ and isoprene fluxes, during 6-19 June are presented in Fig. 4a. Isoprene fluxes exhibited strong diurnal patterns in which emissions progressively increased after sunrise, reaching peak values during the 1500-1800 LT period, and rapidly declined after sunset (Fig. 4a). During spring, averaged maximum canopy isoprene emissions reached approximately $6 \mathrm{nmol}\left(\mathrm{C}_{5} \mathrm{H}_{8}\right) \mathrm{m}^{-2}$ (ground area) $\mathrm{s}^{-1}$, with peak values of $10 \mathrm{nmol} \mathrm{m} \mathrm{m}^{-2} \mathrm{~s}^{-1}$ being measured during the middle of June. Maximum isoprene fluxes occurred late in the afternoon and coincided with peak canopy temperature of $20^{\circ} \mathrm{C}$ (Fig. 4a). Despite the link between isoprene biosynthesis and foliage $\mathrm{CO}_{2}$ uptake (Monson 
and Fall 1989; Sharkey et al. 1991), at the plant canopy scale $\mathrm{CO}_{2}$ fluxes lagged isoprene fluxes. For instance, averaged maximum $\mathrm{CO}_{2}$ fluxes $\left[-20 \mu \mathrm{mol}\left(\mathrm{CO}_{2}\right) \mathrm{m}^{-2}\right.$ $\mathrm{s}^{-1}$ ] coincided when peak PAR levels were measured during 1200-1500 LT, whereas highest isoprene fluxes occurred when the canopy was warmest during 1500 1800 LT (Fig. 4a). Although by the middle of June the aspen forest had attained its maximum capacity to take up $\mathrm{CO}_{2}\left(-25 \mu \mathrm{mol} \mathrm{m} \mathrm{m}^{-2} \mathrm{~s}^{-1}\right)$, the isoprene emissions continued to increase until the beginning of July.

At this boreal forest site, we frequently calculated isoprene deposition that occurred primarily during the evening (Fig. 4a), but occasionally observed deposition during the 1000-1400 LT period. Because the underlying source strength of isoprene was the same regardless of wind direction, we cannot explain the middleof-the-day isoprene deposition. It is possible that advection of isoprene-laden air may have contributed to the higher isoprene concentrations measured aloft. The hazelnut plants (with an LAI of 3.4) underneath the aspen trees may have served as a sink for isoprene. Others (Baldocchi et al. 1995) have also determined occasional isoprene deposition during the middle of the day.

At this remote forested site we observed unusual patterns in ambient isoprene mixing ratios. A common feature observed throughout the growing season was the precipitous declines in isoprene levels measured as sunset approached (Fig. 4b). In early June, isoprene mixing ratios exhibited a distinct diurnal variation with levels of $0.01 \mathrm{ppbv}$ before and immediately after sunrise, increasing with time through the morning and early afternoon to nearly 2 ppbv, which coincided with peak canopy temperature, decreasing as evening approached (Fig. 4b). The noontime patterns of isoprene mixing ratios are consistent with measurements reported for southern broadleafed and mixed temperate forests (Baldocchi et al. 1995; Fuentes et al. 1996; Guenther et al. 1996). As evening approached, the isoprene levels measured close to the canopy ( $27 \mathrm{~m}$ above ground surface) declined at a faster rate than the ones detected away from the forest. This observation suggests that both deposition (Fig. 4b) and chemical processing may have contributed to the rapidly declining isoprene levels.

To represent averaged isoprene fluxes for the middle of the growing season, we combined the flux data obtained during 13 July-9 August (Fig. 5a). Based on diurnal leaf- and canopy-based measurements, the aspen forest attained its maximum capacity to produce isoprene by the beginning of July (Fig. 2). Therefore, the data reported in Fig. 5a represent maximum seasonal isoprene fluxes reaching averaged peak values of approximately $28 \mathrm{nmol} \mathrm{m}^{-2} \mathrm{~s}^{-1}$. Compared to measurements made in June, canopy $\mathrm{CO}_{2}$ fluxes changed little and reached averaged maximum values of $-20 \mu \mathrm{mol}$ $\mathrm{m}^{-2} \mathrm{~s}^{-1}$. Even during the middle of the growing season, diurnal maximum $\mathrm{CO}_{2}$ fluxes lagged isoprene emissions. As in the springtime, maximum isoprene fluxes occurred during the same time (1200-1500 LT) when the canopy experienced peak temperatures of about $25^{\circ} \mathrm{C}$. When the canopy warmed to about $30^{\circ} \mathrm{C}$, isoprene fluxes became large, often reaching values of approximately $40 \mathrm{nmol} \mathrm{m}^{-2} \mathrm{~s}^{-1}$ (Fig. 5a). These extreme values are within the range of previously reported isoprene fluxes $\left(<90 \mathrm{nmol} \mathrm{m}{ }^{-2} \mathrm{~s}^{-1}\right)$ for oak and aspen forests situated in southern latitudes (Baldocchi et al. 1995; Fuentes et al. 1996; Geron et al. 1997; Guenther et al. 1996). However, during the middle of the growing season, the averaged peak isoprene fluxes of $28 \mathrm{nmol} \mathrm{m}^{-2}$ $\mathrm{s}^{-1}$ are lower than reported values $\left(40-60 \mathrm{nmol} \mathrm{m}^{-2}\right.$ $\mathrm{s}^{-1}$ ) for (aspen and oak) forests with comparable isoprene active biomass density distribution (for our boreal forest the active isoprene biomass density was $144 \mathrm{~g}$ $\mathrm{m}^{-2}$ ).

During the middle of the growing season, ambient isoprene mixing ratios exhibited an unusual pattern with one peak occurring around $0900-1000$ LT and a second one taking place at 1800-2000 LT (Fig. 4b). During these times the isoprene mixing ratios averaged 5 ppbv, with extreme high values approaching $16 \mathrm{ppbv}$. As in the spring, ambient isoprene levels rapidly decreased as evening approached likely in response to isoprene deposition and chemical processing. The lower isoprene mixing ratios measured during $1100-1800$ LT can in part be explained by the temporal patterns of atmospheric turbulence or eddy diffusivities. In contrast to the springtime period (Fig. 4b), the eddy diffusivities in the summer period (Fig. 5b) exhibited a more pronounced diurnal variation. For example, the diffusivities remained low $\left(<0.3 \mathrm{~m} \mathrm{~s}^{-1}\right.$; this form of eddy diffusivities already includes the effect of height) until 1000 LT and thereafter increased rapidly reaching peak values ( $\sim 0.8 \mathrm{~m} \mathrm{~s}^{-1}$ ) during 1200-1600 LT (data not shown). Other processes likely contributing to lower isoprene mixing ratios during the midday included photochemical reactions (Gao et al. 1993), particularly the ones with $\mathrm{HO}$ and $\mathrm{O}_{3}$, which can be enhanced by warm air masses.

With the commencement of the autumnal foliage senescence, canopy fluxes progressively declined and averaged diurnal cycles exhibited similar characteristics to those measured in spring. Averaged isoprene fluxes reached nearly $5 \mathrm{nmol} \mathrm{m}^{-2} \mathrm{~s}^{-1}$ (Fig. 6a) with peak values approaching $8 \mathrm{nmol} \mathrm{m}^{-2} \mathrm{~s}^{-1}$. During 26 August-15 September, the maximum isoprene fluxes were measured in the period (1500-1800 LT) when the forest canopy was the warmest $\left(\sim 20^{\circ} \mathrm{C}\right)$, whereas maximum canopy $\mathrm{CO}_{2}$ fluxes took place during the 1200-1500 LT period. In the fall, these uncoupled diurnal patterns of isoprene and $\mathrm{CO}_{2}$ fluxes were observed at alpine aspen forests (Monson et al. 1994). Monson et al. (1994) ascribed the declining patterns in isoprene and $\mathrm{CO}_{2}$ fluxes to the autumnal translocation of nitrogen out of leaves and the breakdown of foliage metabolic activity. However, at the canopy scale isoprene emissions decreased at a faster rate compared to the $\mathrm{CO}_{2}$ flux trends. The data presented 

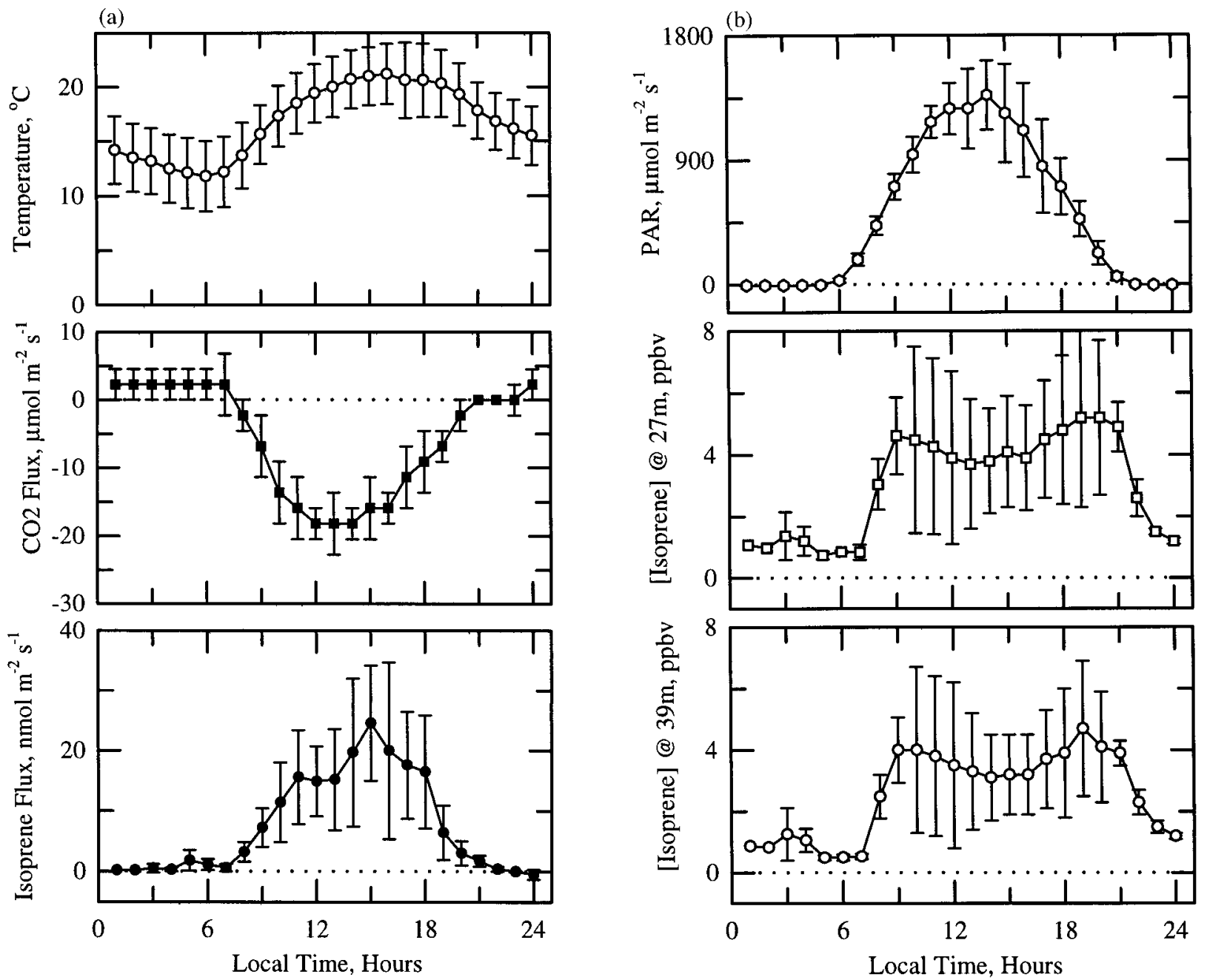

FIG. 5. (a) Averaged diurnal canopy temperature $(\bigcirc)$, carbon dioxide flux density $(\square)$, and isoprene fluxes $(\mathbf{O})$ measured during summer (13 Jul-9 Aug) 1994. The bars denote \pm 1 std dev from the mean values. (b) Averaged diurnal photosynthetically active radiation (PAR, $\diamond)$ and ambient isoprene mixing ratios measured at $27(\square)$ and $39(\bigcirc) \mathrm{m}$ above the ground during summer (13 Jul-9 Aug) 1994. The bars denote \pm 1 std dev from the mean values.

in Fig. 6b show that ambient isoprene mixing ratios exhibited diurnal trends dissimilar to what was observed during the middle of the growing season. The doublepeak cycle in isoprene diurnal variation was less discernible and peak levels occurred during the latter part of the afternoon when maximum averaged mixing ratios attained 1.5 ppbv (Fig. 6b).

Under comparable active biomass distribution, summertime averaged isoprene fluxes measured at the boreal forest are lower (e.g., $25 \mathrm{vs} 50 \mathrm{nmol} \mathrm{m} \mathrm{m}^{-2} \mathrm{~s}^{-1}$ ) than those from temperate and southern forest ecosystems. In part, the discrepancies result because southern forests experience a longer growing season under warmer climatic regimes. Southern forests can also undergo periodic droughts (Baldocchi 1997; Geron et al. 1997), which can induce foliage warming and thus increase isoprene emissions [at the research site, in 1994 conditions were $15 \%$ wetter than the $30-y r$ average; Black et al. (1996)].
In the boreal forest, other features of the climatic forcing variables on isoprene dynamics included frequent occurrences of low temperatures $\left(<10^{\circ} \mathrm{C}\right)$, which may suppress isoprene emissions.

In the case of the aspen forest, low temperatures $\left(<10^{\circ} \mathrm{C}\right)$ lasting as few as $3 \mathrm{~h}$ were sufficient to reduce the amplitude of daily isoprene emissions. Figure $7 \mathrm{a}$ includes an example of isoprene emissions before and after nighttime temperatures dropped below $10^{\circ} \mathrm{C}$. Despite higher temperature and PAR levels, after the low temperature episode isoprene fluxes were lower compared to the previous day (Fig. 7a). In all cases examined, we observed a consistent suppression in emissions after the forest canopy experienced temperatures below $10^{\circ} \mathrm{C}$. In total, four low temperature episodes were identified while measuring canopy isoprene fluxes. Figure $7 b$ provides two additional cases of reduced isoprene fluxes after the exposure of low temperatures. The 

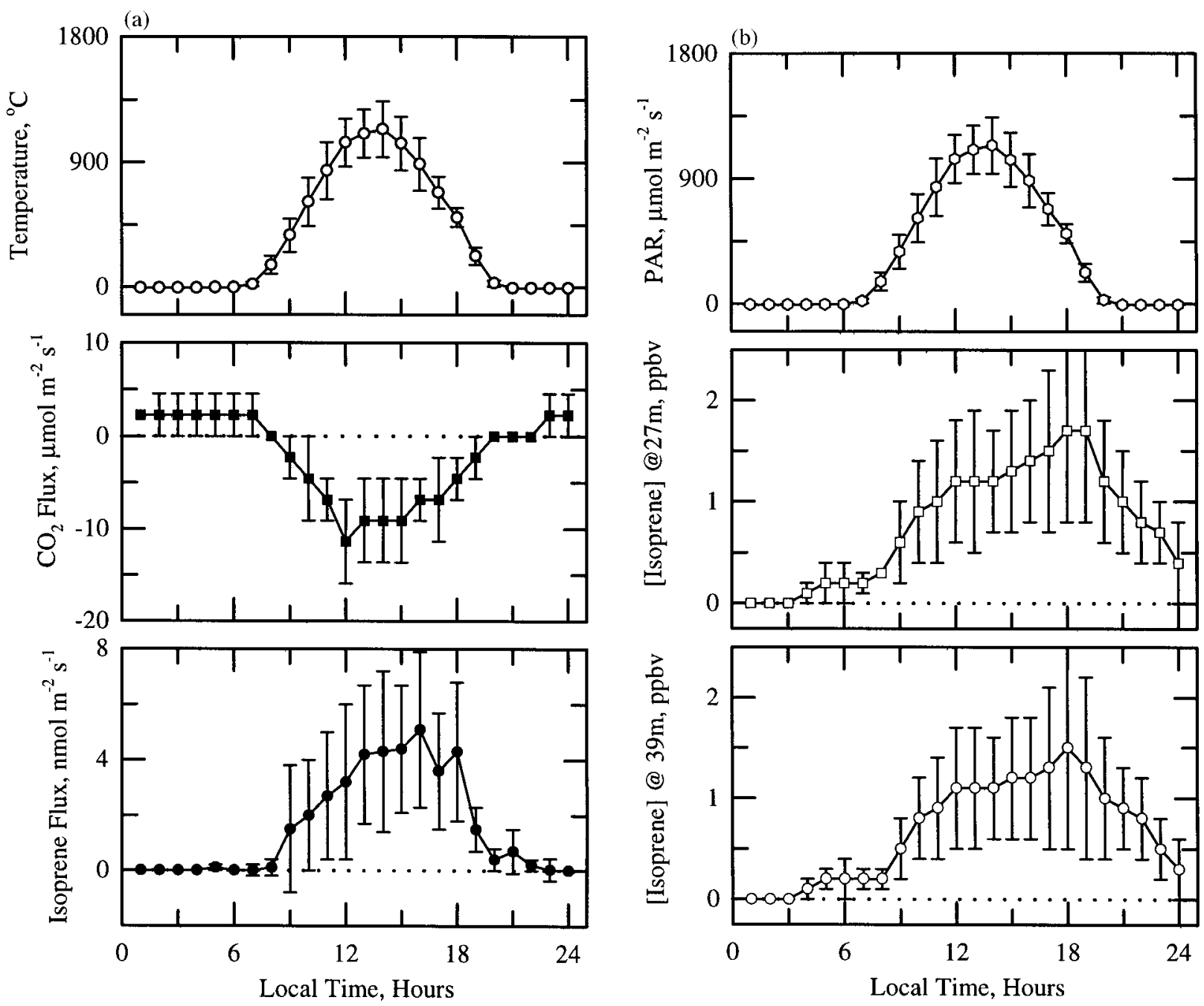

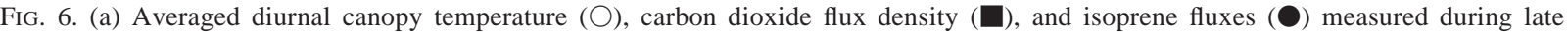
summer (26 Aug-15 Sep) 1994. The bars denote \pm 1 std dev from the mean values. (b) Averaged diurnal photosynthetically active radiation $(\mathrm{PAR}, \diamond)$ and ambient isoprene mixing ratios measured at $27(\square)$ and $39(\bigcirc) \mathrm{m}$ above the ground during late summer (26 Aug-15 Sep) 1994. The bars denote \pm 1 std dev from the mean values.

history of low temperature exposure for both days was similar. In both cases the three preceding nights had temperatures around $5^{\circ} \mathrm{C}$, whereas daytime maximum temperature reached $16^{\circ} \mathrm{C}$. For Fig. $7 \mathrm{~b}$, the observed discrepancies in the diurnal isoprene fluxes likely resulted due to differences in PAR levels. Measured isoprene fluxes became large $\left(>15 \mathrm{nmol} \mathrm{m}^{-2} \mathrm{~s}^{-1}\right) 2-3$ days after the low temperature occurrences (data not shown). After exposure to low temperatures a general feature of diurnal isoprene emission patterns was that maximum fluxes did not necessarily coincide when temperature was highest (Fig. 7). At the leaf level, others studies give evidence of reduced isoprene emissions in response to low temperatures. For example, Sharkey and Loretto (1993) measured low isoprene emissions $(\sim 0.5 \mathrm{nmol}$ $\mathrm{m}^{-2} \mathrm{~s}^{-1}$ ) when kudzu (Pueraria lobata) leaves were grown at $19^{\circ} \mathrm{C}$, but emissions increased $\left(\sim 15 \mathrm{nmol} \mathrm{m}^{-2}\right.$ $\mathrm{s}^{-1}$ ) when the growth temperature was raised to $24^{\circ} \mathrm{C}$.

The documented cases of reduced fluxes after the occurrences of low temperature were too few to examine whether changes occurred in the basal isoprene emission rates because of low temperature exposure. To further investigate the influence of low temperature on isoprene emissions, the noontime ambient isoprene mixing ratios during and after the low temperature episodes were segregated. Furthermore, to account for influences of atmospheric mixing on ambient isoprene levels, isoprene mixing ratios were multiplied by the friction velocity $\left(u_{*}\right)$. The resulting quantities (in units of ppbv $\mathrm{m} \mathrm{s}^{-1}$ ) serve as surrogate isoprene fluxes. To include the effects of both temperature and PAR, the calculated quantities were further analyzed within the framework of the iso- 

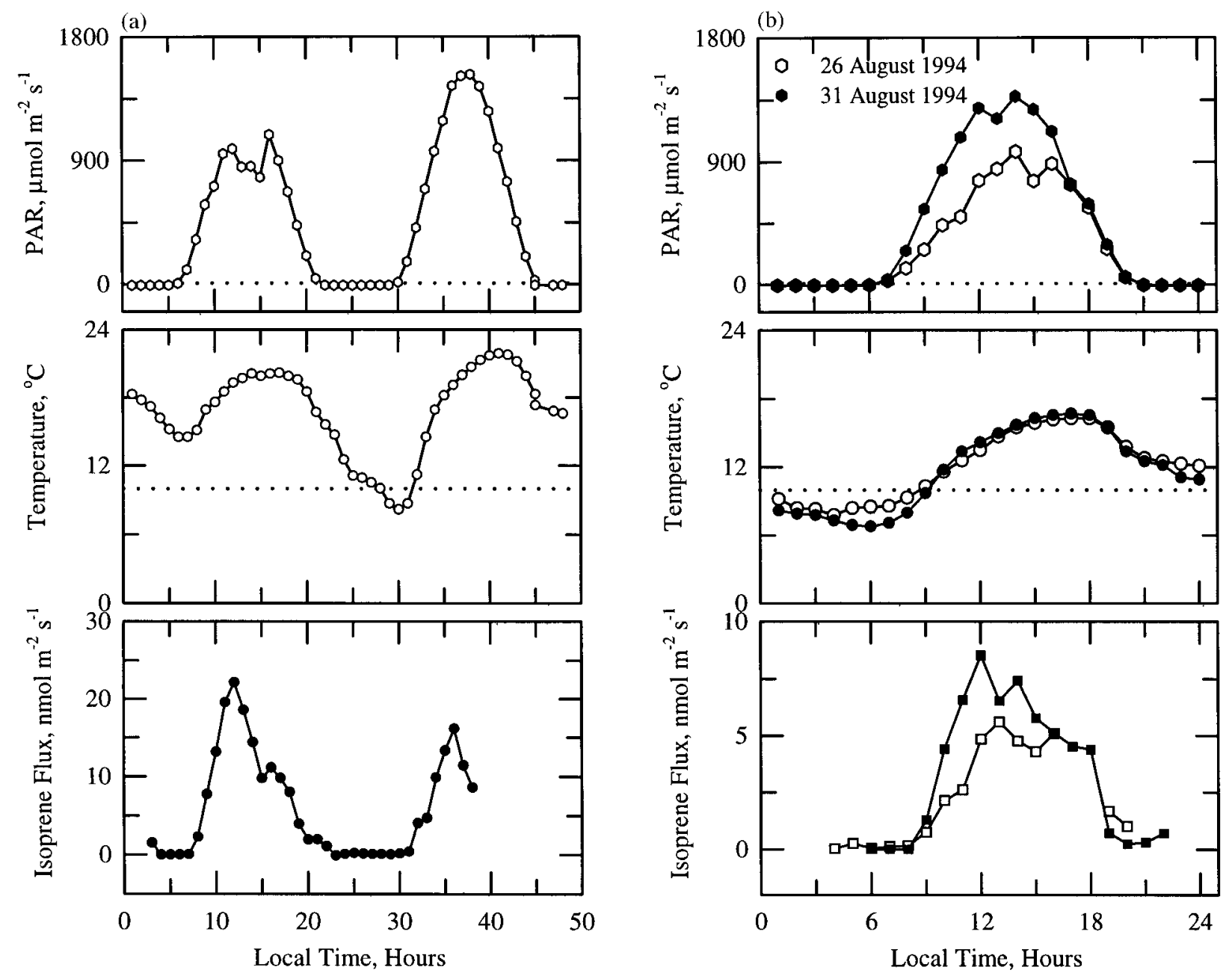

FIG. 7. (a) Diurnal photosynthetically active radiation (PAR, $\diamond)$, canopy temperature $(\bigcirc)$, and isoprene flux densities $(\bigcirc)$ measured before and after low nighttime temperatures (3-4 Aug 1994).(b) Diurnal photosynthetically active radiation (PAR, $\diamond$ ), canopy temperature, and isoprene flux densities measured after low nighttime temperatures. Open and closed symbols denote data for 26 and 31 Aug 1994 , respectively.

prene emission algorithm (Guenther et al. 1993) detailed in section 4 [Eqs. (2)-(4)]. Regression analysis (Fig. 8) was done between temperature and light modulating functions $\left[f\left(T_{L}\right) f(\mathrm{PAR})\right]$ and surrogate fluxes. Although the correlation was low $\left(R^{2}=0.24\right)$, subsequent to the low temperature episodes the slope of the regression line declined by a factor of nearly 3 compared to the case with no low temperature influence. The results (Figs. 7 and 8) indicate that prolonged exposure to low temperature may modify the basal emission rate regimes.

To determine the amount of aspen forest carbon assimilation that was emitted as isoprene, during 10001600 LT (the time period when $\mathrm{CO}_{2}$ fluxes were most reliable) we calculated the percentage of carbon fixed in gross canopy photosynthesis and reemitted to the atmosphere as isoprene. In the calculations (Fig. 9) we considered that the hazelnut understory accounted for $32 \%$ (Black et al. 1996) of the gross canopy photo- synthesis measured at $39 \mathrm{~m}$ above ground. The percentage of carbon assimilation lost in isoprene emission increased with temperature (Fig. 9). At the foliage level, Monson and Fall (1989) and Harley et al. (1996) reported similar relationships for aspen and sweetgum (Liquidambar styraciflua) leaves, respectively. For the aspen forest, the amount of carbon lost in isoprene emission was between $0.1 \%$ and $3.2 \%$ of that assimilated through canopy photosynthesis. When all data (Fig. 9) were combined, the carbon introduced to the atmosphere in the form of isoprene amounted to 0.7 $\pm 0.6 \%$ but for the temperature range $20^{\circ}-25^{\circ} \mathrm{C}$ the value increased to $1.3 \pm 0.4 \%$. These values are within the range $(<8 \%)$ of previously reported data for aspen leaves (Fuentes et al. 1996; Monson and Fall 1989; Sharkey et al. 1991). Under the environmental conditions experienced during 1994, canopy isoprene fluxes did not represent substantial carbon losses from the aspen boreal forest. 


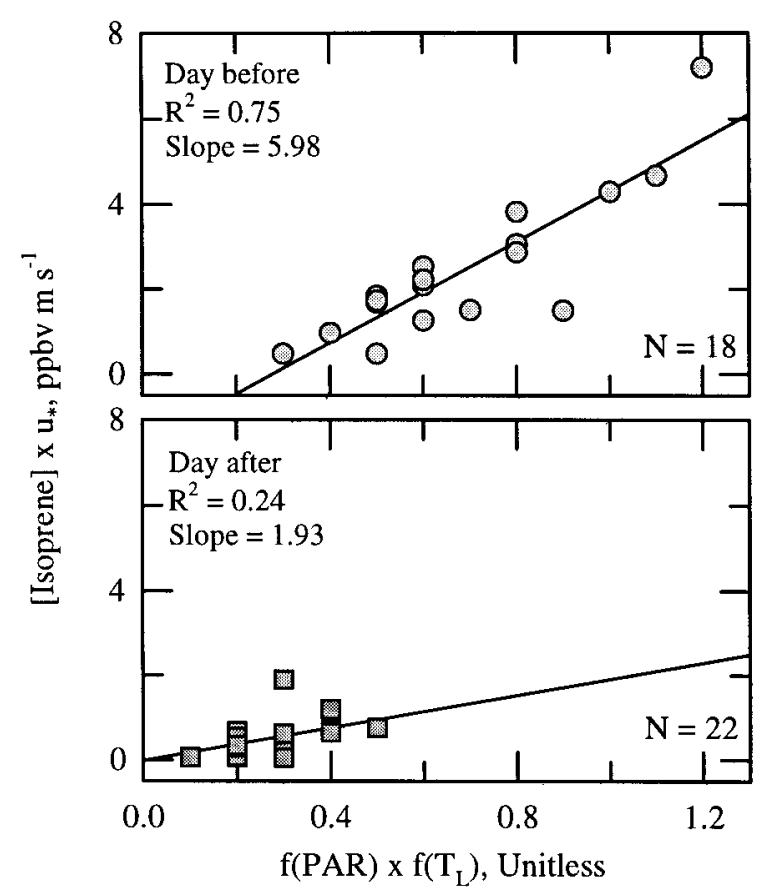

FIG. 8. Relationship between light and temperature functions [see Eqs. (3) and (4) in section 4] and ambient isoprene mixing ratios before (O) and after $(\boldsymbol{\square})$ low nighttime temperatures. The symbol $N$ denotes number of data points included in the analysis.

\section{Modeling isoprene emissions}

A central goal of this study is to assess uncertainties associated with seasonal isoprene emissions. With the data presented above, we determined isoprene emissions throughout the growing season by applying a one-dimensional, multilayered canopy model. We employed the algorithm developed by Guenther et al. (1993) to integrate leaf-based isoprene emission rates $\left(E_{L}\right)$ to the canopy scale. At the leaf level, isoprene emission rates are obtained using a standard emission factor $\left(E_{S}\right)$ and modulating $E_{S}$ using leaf temperature $\left[f\left(T_{L}\right)\right]$ and PAR $[f(\mathrm{PAR})]$ functions as shown in Eq. (2):

$$
E_{L}=E_{\mathrm{s}} f(\mathrm{PAR}) f\left(T_{L}\right),
$$

where $E_{S}$ is defined at a specified leaf temperature $\left(T_{L}\right)$ and intercepted PAR. The modulating functions, $f(\mathrm{PAR})$ and $f\left(T_{L}\right)$, are nondimensional and adjust the emission rate according to variations of leaf temperature and intercepted PAR. Guenther et al. (1993) developed Eq. (3) to describe the light influence on emissions and assumed a value of 1.0 at PAR $=1000 \mu \mathrm{mol} \mathrm{m}^{-2} \mathrm{~s}^{-1}$ :

$$
f(\mathrm{PAR})=\frac{\alpha C_{L} \mathrm{PAR}}{\sqrt{1+(\alpha \mathrm{PAR})^{2}}} .
$$

The $\alpha\left[\mathrm{m}^{-2} \mathrm{~s}^{-1} \mu \mathrm{mol}^{-1}\right.$ (quanta)] and $C_{L}$ are empirical coefficients derived from emission rate measurements. The temperature modulating function, $f\left(T_{L}\right)$, defines the temperature dependency of enzymatic activity responsible for isoprene emissions. It takes the values of 1.0

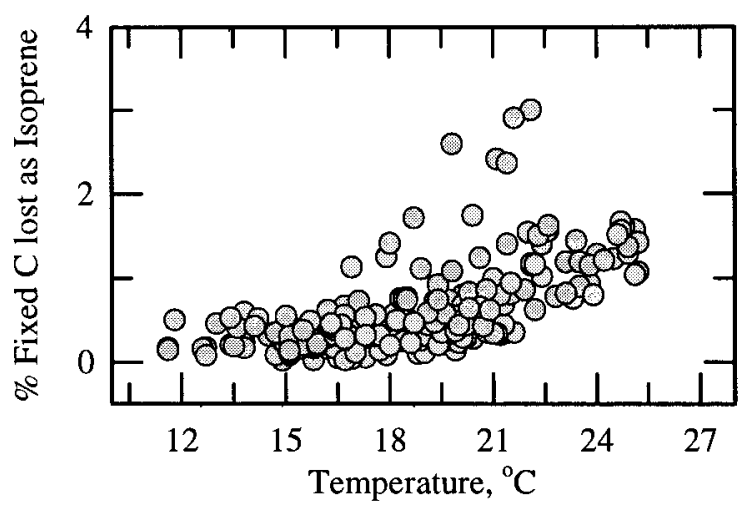

FIG. 9. The percentage of the aspen forest photosynthetically fixed carbon introduced to the atmosphere in the form of isoprene as a function of temperature.

at temperature $T_{S}(303 \mathrm{~K})$ and is given by Eq. (4) (Guenther et al. 1993):

$$
f\left(T_{L}\right)=\frac{\exp \left(\frac{C_{T 1}\left(T_{L}-T_{S}\right)}{R T_{L} T_{S}}\right)}{1+\exp \left(\frac{C_{T 2}\left(T_{L}-T_{\mathrm{Opt}}\right)}{R T_{L} T_{S}}\right)},
$$

where $R$ is the universal gas constant $\left(=8.314 \mathrm{~J} \mathrm{~K}^{-1}\right.$ $\left.\mathrm{mol}^{-1}\right), T_{L}$ is the leaf temperature $(\mathrm{K})$, and $T_{\mathrm{Opt}}$ is the optimum temperature (K). The $C_{T 1}$ and $C_{T 2}$ coefficients represent the activation and deactivation energies $(\mathrm{J}$ $\mathrm{mol}^{-1}$ ), respectively.

To derive isoprene emissions at the forest canopy level, PAR and leaf temperature must be known with canopy depth. For this study, the leaf temperature profile was not measured. Therefore, to apply $f\left(T_{L}\right)$ inside the canopy, $T_{L}$ in each layer was determined from ambient temperature profile measurements. As confirmed from infrared thermometer and profile measurements, the trembling aspen foliage and air had similar temperatures under daytime conditions. The PAR levels inside the forest canopy were obtained using a bi-Lambertian radiative transfer model, which is described below.

\section{a. Estimating photosynthetically active radiation}

To determine PAR distribution within the canopy, we used a two-stream approximation model originally developed by Dickinson (1983) and recently revised by $\mathrm{Gu}$ (1998). The two-stream model is used here because it provides robust analytical solutions for diffuse and direct beam radiation separately. The model treats the forest as an active medium in partitioning the incoming radiation stream into intercepted, reflected, transmitted, and absorbed components. Such processes are incorporated in the radiation propagation Eq. (5) (Dickinson 1983): 


$$
\left\{\begin{array}{l}
-\bar{\mu} \frac{d F \uparrow}{d L}+[1-(1-\beta) \omega] F \uparrow-\omega \beta F \downarrow=\omega \bar{\mu} K \beta_{0} e^{(-K L)}, \\
\bar{\mu} \frac{d F \downarrow}{d L}+[1-(1-\beta) \omega] F \downarrow-\omega \beta F \uparrow=\omega \bar{\mu} K\left(1-\beta_{0}\right) e^{(-K L)},
\end{array}\right.
$$

where $F \uparrow$ and $F \downarrow$ represent the upward and downward diffuse radiative fluxes, respectively, normalized to the incident PAR measured above the forest; $K$ is the light extinction coefficient; $\omega$ denotes the PAR leaf scattering coefficient and equals the sum of the leaf reflection $(\alpha)$ and transmission $(\Psi)$ coefficients; $L$ is the downward cumulative leaf area index; $\mu$ is the average inverse diffuse optical depth per unit leaf area; and $\beta$ and $\beta_{0}$ are the upscatter parameters for the diffuse and direct beam, respectively. The diffuse upscatter parameter $\beta$ can be obtained from the analysis of Norman and Jarvis (1975), and is defined as

$$
\beta=\frac{\left[\alpha+\Psi+(\alpha-\Psi) \overline{\mu_{L}^{2}}\right]}{2 \omega},
$$

where $\mu_{L}$ is the cosine of the leaf inclination angle and the overbar denotes the ensemble average for the canopy. The direct beam upscatter parameter $\beta_{0}$ is derived in Dickinson (1983):

$$
\beta_{0}=\frac{1+\bar{\mu} K}{\omega \bar{\mu} K} a_{s}(\mu),
$$

where $a_{s}(\mu)$ is the single scattering albedo for a semiinfinite canopy and is determined from

$$
a_{s}(\mu)=\omega \int_{0}^{1} \frac{\mu^{\prime} \Gamma\left(\mu, \mu^{\prime}\right)}{\mu G\left(\mu^{\prime}\right)+\mu^{\prime} G(\mu)} d \mu^{\prime},
$$

where $\mu$ is the cosine of solar zenith angle; $G(\mu)$ represents the relative projected area of leaf elements in the direction of $\mu$ and equals 0.5 for spherically distributed leaf canopies (Ross 1981). The azimuthally averaged area scattering function, $\Gamma\left(\mu, \mu^{\prime}\right)$, defines the fraction of the radiant energy in the direction of $\mu$ that is scattered by a unit area of leaf elements into the direction of $\mu^{\prime}$. According to Myneni et al. (1989), $\Gamma\left(\mu, \mu^{\prime}\right)$ can be expressed as

$$
\begin{aligned}
\Gamma\left(\mu, \mu^{\prime}\right)=\int_{0}^{1} g_{L}\left(\mu_{L}\right)[ & \alpha \Pi^{+}\left(\mu, \mu^{\prime}, \mu_{L}\right) \\
& \left.+\Psi \Pi^{-}\left(\mu, \mu^{\prime}, \mu_{L}\right)\right] d \mu_{L} .
\end{aligned}
$$

In Eq. (9), $g_{L}\left(\mu_{L}\right)$ is the leaf orientation distribution function and equals 1 for spherically distributed leaf canopies (Ross 1981), and

$$
\begin{aligned}
\Pi^{ \pm} & \left(\mu, \mu^{\prime}, \mu_{L}\right) \\
& = \pm \frac{1}{4 \pi^{2}} \int_{0}^{2 \pi} d \varphi \int_{0}^{2 \pi}\left(\boldsymbol{\Omega}_{L} \cdot \boldsymbol{\Omega}\right)\left(\boldsymbol{\Omega}_{L} \cdot \boldsymbol{\Omega}^{\prime}\right) d \varphi_{L}
\end{aligned}
$$

where $\boldsymbol{\Omega}, \boldsymbol{\Omega}_{\mathrm{L}}$, and $\boldsymbol{\Omega}^{\prime}$ represent the solar beam direction $(\mu, \varphi)$, leaf normal orientation $\left(\mu_{\mathrm{L}}, \varphi_{L}\right)$, and scattered direction $\left(\mu^{\prime}, \varphi^{\prime}\right)$, respectively; $\left(\boldsymbol{\Omega}_{L} \cdot \boldsymbol{\Omega}\right)$ and $\left(\boldsymbol{\Omega} \cdot \boldsymbol{\Omega}^{\prime}\right)$ represent the cosine of the angle between $\boldsymbol{\Omega}_{L}$ and $\boldsymbol{\Omega}$, $\boldsymbol{\Omega}_{L}$ and $\boldsymbol{\Omega}^{\prime}$, respectively. The average inverse diffuse optical depth per unit leaf area, $\bar{\mu}$, was obtained from (Sellers 1985)

$$
\bar{\mu}=\int_{0}^{1} \frac{\mu}{G(\mu)} d \mu .
$$

The light extinction coefficient $K$ is defined as the ratio of $G(\mu)$ to $\mu$. Finally, the analytical solution to Eq. (5) is

$$
\left\{\begin{array}{l}
F \downarrow=\alpha_{1} e^{-K L}+\alpha_{2} e^{-\alpha_{3} L}+\alpha_{4} e^{\alpha_{3} L}, \\
F \uparrow=\alpha_{5} e^{-K L}+\alpha_{6} e^{-\alpha_{3} L}+\alpha_{7} e^{\alpha_{3} L},
\end{array}\right.
$$

where $\alpha_{1}, \alpha_{2}, \ldots, \alpha_{7}$ are coefficients derived from algebraic combinations of parameters in Eq. (5). Expressions for $\alpha_{1}, \alpha_{2}, \ldots, \alpha_{7}$ can be found in Sellers (1985). For the incident diffuse radiation, the direct radiation term on the right-hand side of Eq. (5) should be dropped and the solution can be found in Sellers (1985).

The two-stream approach has been extensively applied to study radiative transfer in plant canopies (Dickinson 1983; Sellers 1985; Kimes et al. 1987; Dickinson et al. 1990; Joseph et al. 1996). However, Gu (1998) identified two shortcomings in the original two-stream model and made relevant revisions. The original twostream model cannot deal with foliage clumpiness. Most plant canopies have leaves grouped into crowns, branches, and shoots, and effectively alter the radiation regime (Chen et al. 1997). The clumping of foliage reduces the optical depth and thus results in more radiation transmission. Therefore, for a clumped canopy, it is the effective LAI, not the actual LAI, that determines the radiation transmission. The effective LAI is given as the product of the actual LAI and the clumping factor, a characteristic parameter for a given canopy (Chen and Cihlar 1995; Chen et al. 1997). To account for the effects of clumpiness, the effective LAI is used in this study to replace the actual LAI in the two-stream radiation equations. In this study, the seasonal clumping factor (whose value changed from 0.70 to 0.85 ) was derived from the relationship developed by Chen et al. (1997) for the aspen forest.

Another weakness of the original two-stream model is that it assumes isotropic scattering by leaf elements while typical values of leaf reflection coefficients are nearly twice as much as those of leaf transmission coefficients in both the visible and near-infrared regions. This unrealistic assumption can cause significant errors in the estimation of canopy reflectance and transmission. Better model performance was found when the bi-Lambertian leaf scattering model (Ross and Nilson 1968; Myneni et al. 1989) replaces the isotropic leaf scattering model in the two-stream model ( $\mathrm{Gu}$ 1998). We use the bi-Lambertian leaf scattering model in this study.

For the boreal aspen forest we assumed that the canopy has a spherical leaf orientation distribution (Chen 
et al. 1997). We also assumed that the vertical LAI density exhibits a triangular LAI distribution with maximum foliage at the $18-\mathrm{m}$ height and no foliage below $15 \mathrm{~m}$ and above $22 \mathrm{~m}$. Throughout the modeling period, for PAR the leaf reflection coefficient $(\alpha)$ and leaf transmission coefficient $(\Psi)$ were considered constant with the values of 0.09 and 0.06 , respectively (Oke 1987, p. 117). We tested the modified two-stream radiative transfer model with spatially averaged radiation data obtained below the forest canopy. Radiometers mounted above the forest gave incoming radiation levels. The dataset used in the mode test included primarily middle of the growing season conditions, canvassing a wide range of radiation regimes that included cloudless and overcast conditions. Model outputs gave close agreement with measurements, with an overall correlation coefficient $(R)$ of 0.90 (Gu 1998).

\section{b. Determining isoprene emission rates}

In order to model the seasonal pattern of isoprene emissions at this site, we need to know how the emission factors changed over the season. Because isoprene records are more complete at the canopy scale we determined $E_{S}$ based on measured canopy fluxes, modeled PAR, and estimated leaf temperature from measurements of air temperature profiles. Thus, given the isoprene active biomass in the forest (represented by the LAI), canopy-based emissions $\left(E_{C}\right)$ can be expressed as

$$
E_{C}=\int_{0}^{\mathrm{LAI}} E_{L} d L=\int_{0}^{\mathrm{LAI}} E_{S} f(\mathrm{PAR}) f\left(T_{L}\right) d L
$$

where $L$ denotes the downward accumulated LAI, starting from the canopy top. The $f(\mathrm{PAR})$ and $f\left(T_{L}\right)$ functions are defined in Eqs. (3) and (4). If we further assume that $E_{S}$ remains constant with canopy depth, then $E_{S}$ can be obtained through

$$
E_{S}=\frac{E_{C}}{\int_{0}^{\mathrm{LAI}} f(\mathrm{PAR}) f\left(T_{L}\right) d L} .
$$

Other studies (Harley et al. 1996; Geron et al. 1994) indicate that $E_{S}$ varies with canopy depth, particularly in forests where substantial amounts of foliage remains under shade. In this study we did not systematically examine how $E_{S}$ varies with canopy depth. On the basis of similar specific leaf area (SLA) measurements made at the crown $(20 \mathrm{~m})$ and bottom (16 $\mathrm{m}$ above ground) of the canopy (SLA $=0.0192 \pm 0.0004 \mathrm{~m}^{2} \mathrm{~g}^{-1}$ ) by the end of June 1994, we assume here invariant $E_{S}$ with canopy depth [this forest allowed $\sim 30 \%$ of the incoming light reach the top of the hazelnut understory; Chen et al. (1997)]. To characterize the required PAR and $T_{L}$ inside the forest, the canopy was divided into 48 layers, each one having a $d L$ value of $0.05 \mathrm{~m}^{2} \mathrm{~m}^{-2}$.

To assess whether the method outlined above provides

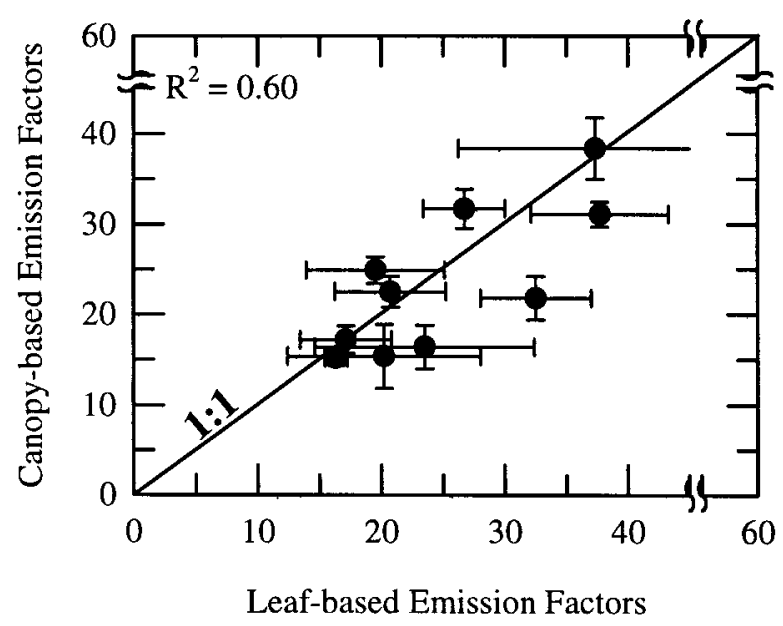

FIG. 10. Comparison between leaf- and canopy-based isoprene emission rates (in units of $\mathrm{nmol} \mathrm{m}^{-2} \mathrm{~s}^{-1}$ ) defined at temperature of $25^{\circ} \mathrm{C}$ and photosynthetically active radiation of $1000 \mu \mathrm{mol} \mathrm{m}^{-2} \mathrm{~s}^{-1}$. The bars denote \pm 1 std dev from the mean values.

reliable outputs, the $E_{S}$ values derived from daily canopy fluxes were compared with emission rates obtained from cuvette measurements (section $3 \mathrm{~b}$ ), which were also normalized at leaf temperature of $25^{\circ} \mathrm{C}$ and PAR $=1000$ $\mu \mathrm{mol} \mathrm{m} \mathrm{m}^{-2} \mathrm{~s}^{-1}$ [i.e., Eqs. (3) and (4)]. The two independent methods of deriving $E_{S}$ yielded acceptable results, with $R^{2}=0.60$ (Fig. 10). Cuvette-based emissions exhibited greater variation but on average were only $8 \%$ greater than canopy-based $E_{S}$ estimates. Accepting this level of uncertainty, we now proceed to determine seasonal isoprene emission rates from the more complete record of canopy fluxes.

\section{c. Seasonal isoprene emissions}

Using the method described above (section $4 \mathrm{~b}$ ), the $E_{S}$ values over the growing season were determined from available canopy fluxes and the results were expressed as a function of day of the year. At this boreal forest, isoprene emissions commenced two weeks after the forest became fully leafed (Figs. 1 and 11). Delays in emissions during spring are consistent with observations at alpine (Monson et al. 1994) and temperate (Fuentes et al. 1995) aspen forests, and are ascribed to reduced enzymatic activity as developing foliage translocates substrates to carry out other physiological functions (Grinspoon et al. 1991; Kuzma and Fall 1993). Maximum emissions occurred during days 200-210 (Fig. 11), with maximal rates of emissions approaching $35 \mathrm{nmol} \mathrm{m}^{-2}$ (leaf area) $\mathrm{s}^{-1}$. These emission rates agree with reported emissions $\left(\sim 30 \mathrm{nmol} \mathrm{m}{ }^{-2} \mathrm{~s}^{-1}\right)$ for aspen foliage (Monson et al. 1994). After the onset of autumnal leaf senescence, isoprene emissions steadily declined in response to lower magnitude of climatic forcing variables and diminished isoprene-emitting substrate. Measurements were suspended before complete leaf fall. As a result, substantial isoprene fluxes (Fig. 


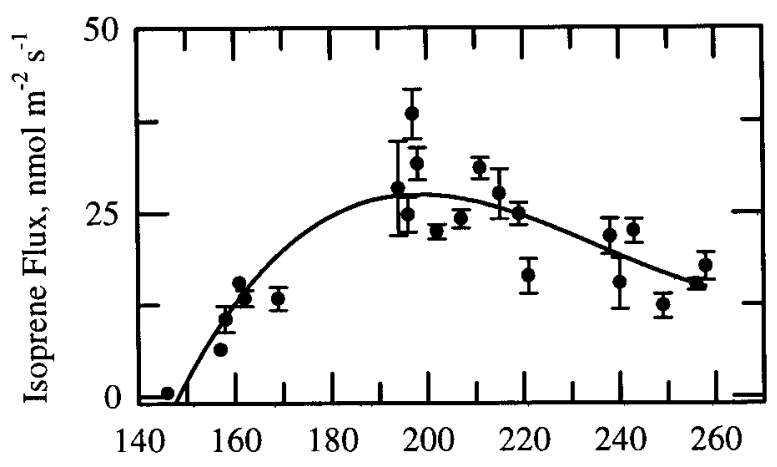

Day of Year

FIG. 11. Seasonal pattern of isoprene emission rates $(\mathbf{O})$ during the 1994 growing season. Emission rates were normalized to $25^{\circ} \mathrm{C}$ and photosynthetically active radiation of $1000 \mu \mathrm{mol} \mathrm{m} \mathrm{m}^{-2} \mathrm{~s}^{-1}$. The bars denote \pm 1 std dev from the mean $(\bigcirc)$ values, and the solid line represents the best fit to data points.

11) were determined by the middle of September when nearly half of the foliage still remained on trees (Fig. 1). Because we did not continuously measure canopy isoprene fluxes, the interactions between low temperature and emissions are not incorporated in the normalized isoprene emission rates (Fig. 11).

\section{d. Modeled canopy isoprene emissions}

Before the canopy model can be applied to derive seasonal fluxes, it is necessary to understand whether it provides realistic isoprene scaling to the canopy dimension. Thus, using leaf-based emission rates (Fig. 10), the model was applied to determine isoprene emissions for the days when both canopy and leaf fluxes were available. The results (Fig. 12) showed that calculated isoprene flux densities compared closely with measurements $\left(R^{2}=0.89\right)$. The model yielded credible results that on average were $14 \%$ greater than measured isoprene fluxes. As reported in previous studies (Baldocchi et al. 1999; Geron et al. 1997; Guenther et al. 1996; Lamb et al. 1996), we attribute this close agreement between modeled and measured fluxes to the proper description of both isoprene active biomass and microclimate characteristics inside the forest canopy. Based on these results (Fig. 12), we conclude that under the growing conditions experienced at our aspen boreal forest (but precluding the influence of low temperatures) the integration of isoprene emissions from leaf to canopy dimensions can be realistically achieved.

Given that the canopy model calculated realistic fluxes on a daily basis, we then investigated uncertainties associated with seasonal isoprene emissions. We applied the model to examine three emission scenarios. One scenario involved the use of a seasonally adjusted emission factor $\left[E_{S}(t)\right]$ as established from the normalized fluxes reported in Fig. 11. This case was contrasted with model outputs using a constant emission factor. For the

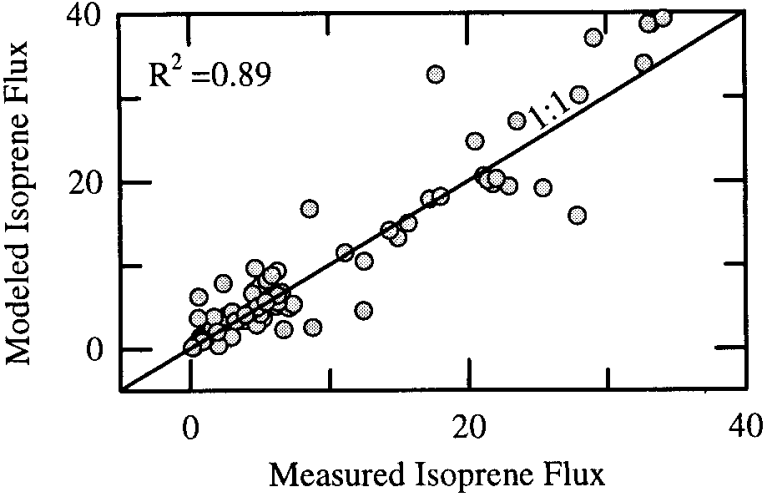

FIG. 12. Comparison between measured and calculated $(\bigcirc)$ flux densities of isoprene (in units of nmol m $\mathrm{m}^{-2} \mathrm{~s}^{-1}$ ) for the aspen forest during selected days (16 Jul-12 Sep) of the 1994 growing season.

later, we incorporated in the model the seasonal averaged isoprene flux $\left[E_{S}=15 \mathrm{nmol} \mathrm{m}{ }^{-2}\right.$ (leaf area) s$\left.{ }^{-1}\right]$. Compared to seasonally adjusted values, the use of a constant emission rate gave higher isoprene fluxes during early and latter parts of the growing season, whereas close agreement resulted in the middle of the season (data not shown). Using a constant emission rate, the seasonally integrated isoprene emissions were underestimated by $12 \%$ (Fig. 13). Since the discrepancy is within measurement uncertainties, this level of agreement is adequate for most applications of isoprene emission inventories. However, the difficulty of choosing an appropriate averaged emission factor remains unresolved. To illustrate how unreliable isoprene inventories become, we considered a third modeling scenario using an emission factor that represented averaged isoprene emissions $\left(E_{S}=28 \mathrm{nmol} \mathrm{m}^{-2} \mathrm{~s}^{-1}\right)$ measured during the middle of the growing season. This emission factor is similar to the rate $\left(=26 \mathrm{nmol} \mathrm{m}^{-2} \mathrm{~s}^{-1}\right)$ recommended for plants of the genus Populus (Guenther et al. 1994).

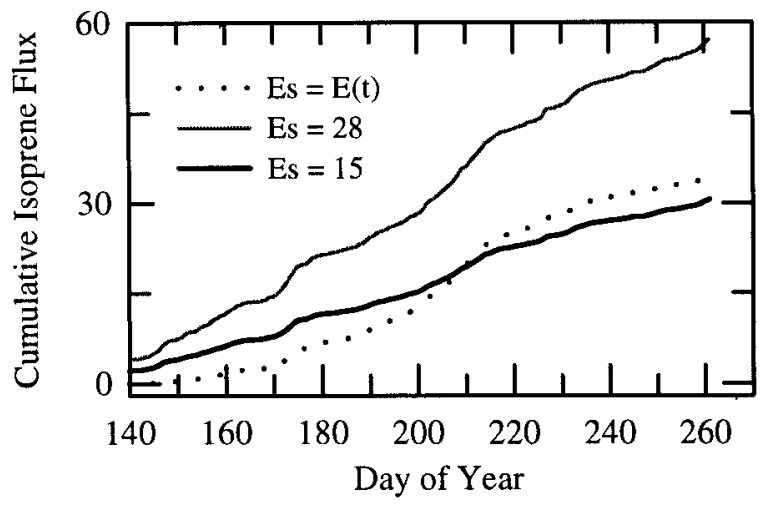

FIG. 13. Cumulative isoprene fluxes during the 1994 growing season using seasonally adjusted (…...) and constant emission rates. For the latter, the data denoted by the solid line (- - ) used an emission factor of $15 \mathrm{nmol} \mathrm{m} \mathrm{m}^{-2} \mathrm{~s}^{-1}$, whereas the thin line (-) incorporated an emission rate of $28 \mathrm{nmol} \mathrm{m}^{-2} \mathrm{~s}^{-1}$. Cumulative daily

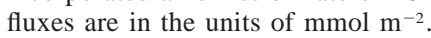


Applying the emission rate of $28 \mathrm{nmol} \mathrm{m} \mathrm{m}^{-2} \mathrm{~s}^{-1}$, we calculated a $65 \%$ overestimate of seasonally integrated isoprene emissions (Fig. 13). With this emission rate the model estimated realistic isoprene fluxes during the middle of the growing season but failed to describe the seasonal emission patterns established with the seasonally adjusted emission rates. Although in the opposite direction, larger deviations would be expected if we used the emission rates $\left(\sim 5 \mathrm{nmol} \mathrm{m}{ }^{-2} \mathrm{~s}^{-1}\right)$ incorporated in the modeling systems to derive inventories from forests in southern Canada (Fuentes et al. 1995). Based on the integrated, observed seasonal canopy isoprene emissions we calculated that the boreal aspen forest with an active biomass of $144 \mathrm{~g} \mathrm{~m}^{-2}$ during 1994 produced 34 mmol of isoprene per square meter.

\section{Summary and conclusions}

The information reported here represents a unique dataset of seasonal isoprene fluxes from a forest ecosystem whose isoprene source came from trees of the same species and age. Such seasonal isoprene fluxes can be used to test and evaluate inventory modeling systems. At this boreal forest, the onset of isoprene emissions occurred two weeks after the forest attained its maximum leaf area. Representing emissions during spring and scaled to the leaf level, averaged isoprene fluxes approached $10 \pm 5 \mathrm{nmol} \mathrm{m} \mathrm{m}^{-2} \mathrm{~s}^{-1}$. During the middle of the growing season averaged isoprene emissions amounted to $28 \pm 4 \mathrm{nmol} \mathrm{m}^{-2} \mathrm{~s}^{-1}$, whereas late summer values reached $16 \pm 2 \mathrm{nmol} \mathrm{m} \mathrm{m}^{-2} \mathrm{~s}^{-1}$. These isoprene capacities were normalized to $25^{\circ} \mathrm{C}$ and PAR of 1000 $\mu \mathrm{mol} \mathrm{m} \mathrm{m}^{-2} \mathrm{~s}^{-1}$.

In addition to the seasonal controls dictated by the inherent plant metabolic activity, low temperatures $\left(<10^{\circ} \mathrm{C}\right)$ strongly modulated isoprene emissions. The frequent low temperatures observed at the boreal forest caused substantial reductions in the diurnal amplitude of isoprene emissions. Even after the forest had attained its maximum capacity to emit isoprene, following the occurrence of low temperatures, isoprene emissions were suppressed despite favorable temperature regimes to promote large fluxes. Reduced isoprene emissions resulted likely due to diminished enzymatic activity in leaves.

Using a multilayered canopy model, we confirmed that realistic isoprene emissions can be obtained for forests if emission rates, active biomass, and influencing environmental variables are properly characterized as they vary with depth in the canopy. Given that emissions substantially change with growing season, it is necessary to determine appropriate emission rates to derive inventories for either short- or long-term temporal scales. In this study, we found that with an averaged emission rate $\left(=15 \mathrm{nmol} \mathrm{m}^{-2} \mathrm{~s}^{-1}\right)$, characterizing prevailing emissions throughout the season, the calculated fluxes exceeded the measured quantities by $12 \%$. However, emission rates representing the middle of the grow- ing season yielded poorer results and the uncertainties exceeded $65 \%$. These results demonstrate the inadequacies of using a single emission rate to characterize seasonal isoprene emissions. To obtain improved emission inventories, modeling systems need to incorporate seasonally adjusted emission factors. In the form of isoprene, the boreal aspen forest lost approximately $1 \%$ of the carbon assimilated through photosynthesis. On average, this did not represent a significant amount of carbon lost but values exceeded 3\% when the temperature was higher than $20^{\circ} \mathrm{C}$.

Acknowledgments. The Atmospheric Environment Service (AES) of Environment Canada sponsored the field project. Special acknowledgments are due to AES scientists Drs. G. den Hartog and H. H. Neumann, and R. M. Staebler for their field support and companionship, and for the enlightening discussions on canopy fluxes. J. Deary of AES contributed with talented technical assistance in operation and maintenance of instrumentation and microclimate data acquisition. P. Makar and R. M. Staebler of AES made comments to improve this manuscript. Three journal reviewers provided excellent comments that resulted in a substantially improved manuscript. The National Aeronautical and Space Administration provided field infrastructure support for the BOREAS project.

\section{REFERENCES}

Baldocchi, D. D., 1997: Measuring and modeling carbon dioxide and water exchange over a temperate broad-leaved forest during the 1995 summer drought. Plant, Cell Environ., 20, 1108-1122.

, A. Guenther, P. Harley, L. Klinger, P. Zimmerman, B. Lamb, and $\mathrm{H}$. Westberg, 1995: The fluxes and air chemistry of isoprene above a deciduous hardwood forest. Philos. Trans. Roy. Soc. London, 235A, 279-296.

— J. D. Fuentes, D. R. Bowling, A. A. Turnipseed, and R. K. Monson, 1999: Scaling isoprene fluxes from leaves to canopies: Test cases over a boreal aspen and a mixed-species temperate forest. J. Appl. Meteor., 38, 885-898.

Black, T. A., and Coauthors, 1996: Annual cycles of water vapour and carbon dioxide fluxes in and above a boreal aspen forest. Global Change Biol., 2, 219-230.

Blanken, P. D., and Coauthors, 1997: Energy balance and canopy conductance of a boreal aspen forest: Partitioning overstory and understory components. J. Geophys. Res., 102, 28 915-28 927.

Chameides, W., R. Lindsay, J. Richardson, and C. Kiang, 1988: The role of biogenic hydrocarbons in urban photochemical smog: Atlanta as a case study. Science, 241, 1473-1475.

Chen, J. M., and J. Cihlar, 1995: Plant canopy gap size analysis theory for improving optical measurements of leaf area index. Appl. Opt., 34, 6211-6222.

, P. D. Blanken, T. A. Black, M. Guilbeault, and S. Chen, 1997: Radiation regime and canopy structure in a boreal aspen forest. Agric. For. Meteor., 86, 107-125.

Dickinson, R. E., 1983: Land surface processes and climate-surface albedos and energy balance. Advances in Geophysics, Vol. 25, Academic Press, 305-353.

_ B. Binty, and M. M. Verstraete, 1990: Relating surface albedos in GCM to remotely sensed data. Agric. For. Meteor., 52, 109131.

Fehsenfeld, F, and Coauthors, 1992: Emissions of volatile organic 
compounds from vegetation and the implications for atmospheric chemistry. Global Geochem. Cycles, 6, 389-430.

Fuentes, J. D., and T. J. Gillespie, 1992: A gas exchange system to study the effects of leaf surface wetness on the deposition of ozone. Atmos. Environ., 26, 1165-1173.

—, D. Wang, G. den Hartog, H. H. Neumann, T. F. Dann, and K. J. Puckett, 1995: Modelled and field measurements of biogenic hydrocarbon emissions from a Canadian deciduous forest. At mos. Environ., 29, 3003-3018.

,,,--- , and,- 1996 : Ambient biogenic hydrocarbon concentrations and isoprene emissions from a mixed deciduous forest. J. Atmos. Chem., 25, 67-95.

Gao, W., M. L Wesely, and I. Y. Lee, 1993: Numerical modeling of turbulent diffusion and chemistry of $\mathrm{NO}_{\mathrm{x}}, \mathrm{O}_{3}$, isoprene, and other reactive trace gases in and above a forest canopy. J. Geophys. Res., 98, 18 339-18 353.

Geron, C. D., A. B. Guenther, and T. E. Pierce, 1994. An improved model for estimating emissions of volatile organic compounds from forests in eastern United States. J. Geophys. Res., 99, $12773-12791$.

— uation in a southern United States bottomland deciduous forest. J. Geophys. Res., 102, 18 889-18 901.

Grinspoon, J., W. D. Bowman, and R. Fall, 1991: Delayed onset of isoprene emission in developing velvet bean (Macuna sp.) leaves. Plant Physiol., 97, 170-174.

Gu, L., 1998. Modeling biosphysical exchanges and micrometeorology in soil-vegetation-atmosphere continuums-Results from a two-story boreal aspen forest. Ph.D. thesis, University of Virginia, $265 \mathrm{pp}$. [Available from University of Virginia, Science and Engineering Library, Clark Hall, Charlottesville, VA 22903.]

Guenther, A. B., P. R. Zimmerman, P. C. Harley, R. K. Monson, and R. Fall, 1993: Isoprene and monoterpene emission rate variability: Model evaluation and sensitivity analysis. J. Geophys. Res., 98, 12 609-12 617.

- - , and L. A. Wildermuth, 1994: Natural volatile organic compound emission rate estimates for U.S. woodland landscapes. Atmos. Environ., 28, 1197-1210.

- and Coauthors, 1995: A global model of natural volatile organic compound emissions. J. Geophys. Res., 100, 8873-8892.

_ relaxed eddy accumulation, surface layer gradient, mixed layer gradient, and mixed layer mass balance techniques. J. Geophys. Res., 101, 18 555-18 567.

Harley, P., A. Guenther, and P. Zimmerman, 1996: Effects of light, temperature and canopy position on net photosynthesis and isoprene emission from sweetgum (Liquidambar styraciflua) leaves. Tree Physiol., 16, 25-32.

Joseph, J. H., J. Iaquinta, and B. Pinty, 1996: The use of two-stream approximations for the parameterization of solar radiative energy fluxes through vegetation. J. Climate, 9, 2326-2336.

Kimes, D. S., P. J. Sellers, and W. W. Newcomb, 1987: Hemispherical reflectance variations of vegetation canopies and implications for global and regional energy budget studies. J. Climate Appl. Meteor., 26, 959-972.

Kuzma, J., and R. Fall, 1993. Leaf isoprene emission rates dependent on leaf development and the level of isoprene synthase. Plant Physiol., 101, 435-440.

Lamb, B., D. Gay, and H. Westberg, 1993: A biogenic hydrocarbon emission inventory for the U.S.A. using a simple forest canopy model. Atmos. Environ., 27, 1673-1690.

— estimating isoprene emissions. J. Geophys. Res., 101, $22787-$ 22797.

Monin, A. S., and A. M. Obukhov, 1954: Basic laws of turbulence mixing in the ground layer of the atmosphere. Acad. Nauk. SSR Trud. Geofiz. Inst., 24, 163-187.

Monson, R. K., and R. Fall, 1989: Isoprene emission from aspen leaves: Influence of environment and relation to photosynthesis and photorespiration. Plant. Physiol., 90, 267-274.

—, C. H. Jaeger, W. W. Adams III, E. M. Diggers, G. M. Silver, and R. Fall, 1992: Relationships among isoprene emission rate, photosynthesis, and isoprene synthase activity as influenced by temperature. Plant Physiol., 98, 1175-1180.

_, P. C. Harley, M. E. Litvak, M. Wildermuth, A. B. Guenther, P. R. Zimmerman, and R. Fall, 1994: Environmental and developmental controls over the seasonal pattern of isoprene emission from aspen leaves. Oecologia, 99, 260-270.

Myneni, R. B., J. Ross, and G. Asar, 1989: A review on the theory of photon transport in leaf canopies. Agric. For. Meteor., 45, 1153.

Neumann, H. H., G. den Hartog, and R. H. Shaw, 1989: Leaf area measurements based on hemispheric photographs and leaf-litter collection in a deciduous forest during autumn leaf-fall. Agric. For. Meteor., 45, 325-345.

Norman, J. M., and P. G. Jarvis, 1975: Photosynthesis in sitka spruce [Picea Ssitchensis (Bong). Car.]. V. Radiation penetration theory and a test case. J. Appl. Ecol., 12, 839-878.

Oke, T. R., 1987: Boundary Layer Climates. 2d ed. Routledge, 435 pp.

Ross, J., 1981: The Radiation Regime and Architecture of Plant Stands. Dr. W. Junk Publishers, 391, pp.

_, and T. Nilson, 1968: A mathematical model of radiation regime of plant cover. Actinometry and Atmospheric Optics, Valgus Publishers, 263-281.

Sellers, P. J., 1985: Canopy reflectance, photosynthesis and transpiration. Int. J. Remote Sens., 8, 1335-1372.

_- and Coauthors, 1995: The Boreal Ecosytem-Atmosphere Study (BOREAS): An overview and early results from the 1994 field year. Bull. Amer. Meteor. Soc., 76, 1549-1577.

Sharkey, T. D., and F. Loreto, 1993: Water stress, temperature, and light effects on the capacity for isoprene emission and photosynthesis of kudzu leaves. Oecologia, 95, 328-333.

, — _ , and C. F. Delwiche, 1991: High carbon dioxide and sun/ shade effects on isoprene emission from oak and aspen tree leaves. Plant, Cell Environ., 14, 333-338.

Simpson, I. J., G. C. Edwards, G. W. Thurtell, G. Den Hartog, H. H. Neumann, and R. M. Staebler, 1997: Micrometeorological measurements of methane and nitrous oxide exchange above a boreal aspen forest. J. Geophys. Res., 102, 29 331-29 341.

Sinclair, T. R., L. H. Allen Jr., and E. B. Lemon, 1975: An analysis of errors in the calculation of energy flux densities above vegetation by a Bowen-ratio profile method. Bound.-Layer Meteor., $8,129-139$.

Young, V. L., B. N. Kieser, S. P. Chen, and H. Niki, 1997: Seasonal trends and local influences on nonmethane hydrocarbon concentrations in the Canadian boreal forest. J. Geophys. Res., 102, 5913-5918. 